\title{
IPTEKS SPT MASA PAJAK PERTAMBAHAN NILAI (PPN) PADA PT CIPUTRA INTERNASIONAL CABANG MANADO
}

\author{
Arisna J. Mantiaha ${ }^{1}$, Syermi Mintalangi ${ }^{2}$ \\ ${ }^{1,2}$ Jurusan Akuntansi, Fakultas Ekonomi dan Bisnis, Universitas Sam Ratulangi, Jl. Kampus Unsrat, Manado, \\ 95115, Indonesia \\ E-mail : arisna.mantiaha@gmail.com
}

\begin{abstract}
Tax is a contribution from the people to the country. Every taxable entrepreneurs report tax reports to the government. One of them is Value Added Tax (VAT). PT Ciputra Internasional Manado report it's Periodic Tax Return of VAT using e-Invoice provided by the Director General Tax. E-Invoice own application used by taxable entrepreneur in carrying out tax obligation. This study wants to provide knowledge in the application of e-Invoice to reporting VAT's periodic tax return. Result of this research showed that PT Ciputra Internasional Manado in reporting Periodic Tax Return of VAT compliance with UU No.42 of 2009, Director General of Tax Regulation No. PER-31/PJ/2017, and Director General of Tax Regulation No. PER-01/PJ/2017.
\end{abstract}

Keywords : Value Added Tax, Reporting, E-Invoice

\section{PENDAHULUAN}

PT Ciputra Internasional Cabang Manado merupakan perusahaan yang beroperasi pada bagian usaha real estate. Dalam kegiatan operasionalnya PT Ciputra Internasional Cabang Manado perlu melakukan pelaporan pajak. Salah satu Pajak yang harus dilaporkan oleh PT Ciputra Internasional cabang Manado adalah Pajak Pertambahan Nilai yang sebelumnya adalah Pajak Penjualan. Pajak penjualan mempunyai beberapa kelemahan salah satunya adalah memiliki tarif yang bermacam-macam sehingga menimbulkan kesulitan dalam pelaksanaannya sedangkan Pajak Pertambahan Nilai hanya menggunakan tarif tunggal sehingga lebih mudah pelaksanaannya. Dalam hal ini, PT Ciputra Internasional Cabang Manado menggunakan e-Faktur. Oleh karena itu, untuk mengetahui apakah penyampaian SPT Masa Pajak Pertambahan Nilai sudah dilakukan dengan baik maka dilakukan studi ini.

\section{TINJAUAN PUSTAKA}

Pajak. Pajak merupakan iuran dari rakyat berupa uang yang dibayarkan kepada negara sesuai dengan Undang-Undang dan tanpa kontraprestasi secara langsung dari negara.

Pajak Pertambahan Nilai (PPN). PPN adalah pajak pungutan atas penyerahan BKP atau Barang Kena Pajak dan JKP atau Jasa Kena Pajak dalam negeri.

E-Faktur. E-Faktur adalah aplikasi atau sistem elektronik yang disediakan oleh Direktur Jendral Pajak bagi Pengusaha Kena Pajak (PKP) untuk melaksanakan kewajiban perpajakan. Dalam e-Faktur terdapat e-SPT dimana e-SPT adalah aplikasi yang digunakan untuk menyampaikan SPT.

Surat Pemberitahuan (SPT). Jangka waktu penyampaian SPT bisa diperpanjang 2 (dua) bulan dari batas waktu yang ditetapkan apabila Wajib pajak menyampaikan pemberitahuan terkait perpanjangan SPT Tahunan. 


\section{METODE DAN TEKNIK PENERAPAN IPTEKS}

\subsection{Metode Penerapan Ipteks}

Penerapan ipteks yang dilaksanakan adalah metode menggunakan Undang-Undang, dan peraturan perpajakan yang berlaku lainnya.

\subsection{Teknik Penerapan Ipteks}

Teknik penerapan ipteks adalah dengan melakukan pengamatan dan diskusi dengan pegawai PT Ciputra Internasional Cabang Manado yang bertanggung jawab dalam pelaporan SPT Masa Pajak Pertambahan Nilai menggunakan e-Faktur berdasarkan Undang-Undang dan peraturan perpajakan yang berlaku lainnya.

\section{PEMBAHASAN}

\subsection{Gambaran Objek Penerapan Ipteks}

PT Ciputra Internasional Cabang Manado adalah bagian dari Group Ciputra yang bergerak di bidang real estate. Ciputra Group didirikan pada tahun 1981 oleh PT Citra Habitat Indonesia. PT Ciputra Internasional Cabang Manado berada di Jl. Winangun Utama Ling III No.1\&2 Winangun 1 Manado, Provinsi Sulawesi Utara. Semenjak tahun 2003 sampai sekarang, PT Ciputra Internasional Cabang Manado masih terus mengembangkan lahan yang ada demikian juga dengan kualitas perumahannya dengan menawarkan konsep perumahan yang unik dan modern.

Patung Tuhan Yesus Memberkati yang menjadi icon kota Manado, kemudian Citraland Water Park, Plaza Getsemani dan Jalan Salib, Lapangan Tenis, Big Ben Tower, Sekolah Citra Kasih, Family Club House, Jogging Track, Cone Sculpture, Badminton Hall, Ruko CitraLand Miracle Walk, Children Playground dan Bike Line merupakan cara Group Ciputra dalam mengembangkan kompleks perumahan dengan state-of-the-art-features untuk memenuhi kebutuhan kota akan perumahan dan peningkatan tempat wisata. Melalui ini CitraLand Manado menjadi trendsetter di provinsi Sulawesi Utara.

SPT Masa Pajak Pertambahan Nilai (PPN) Pada PT Ciputra Internasional Cabang Manado. PT Ciputra Internasional Cabang Manado telah menggunakan aplikasi e-Faktur versi terbaru yaitu aplikasi deskop versi 2.1. Dalam pelaporan SPT Masa Pajak Pertambahan Nilai PT Ciputra Internasional Cabang Manado menjalankan prosedur sebagai berikut: (1) Transaksi; (2) Rekapan Penjualan; (3) Menghitung DPP dan PPN; (4) Input di aplikasi eFaktur; (5) Menginput PPN Keluaran; (6) Menginput PPN Masukan (jika kurang bayar dibayarkan lalu dilaporkan di aplikasi DJP Online sedangkan jika lebih bayar harus di kompensasi ke masa pajak berikutnya).

\subsection{Pembahasan}

Dalam pelaporan SPT Masa Pajak Pertambahan Nilai, PT Ciputra Internasional Cabang Manado melaporkan SPT Masa Pajak Pertambahan Nilai setiap akhir bulan, ini telah sesuai dengan UU No.42 Tahun 2009.

Kemudian untuk Peraturan DJP No. Per-31/PJ/2017 PT Ciputra Internasional Cabang Manado telah melaksanakannya yaitu apabila pembeli BKP atau penerima JKP Orang Pribadi tidak memiliki NPWP maka diwajibkan untuk memberikan NIK atau Nomor Induk Kependudukan sedangkan untuk warga asing harus mencantumkan nomor Paspor.

Selanjutnya untuk Peraturan DJP Nomor Per-01/PJ/2017 sendiri, PT Ciputra Internasional Cabang Manado menyampaikan SPT Masa Pajak Pertambahan Nilai dengan memanfaatkan teknologi informasi yang ada dalam hal ini aplikasi e-Faktur. Melalui aplikasi e-Faktur PT Ciputra Internasional Cabang Manado dapat melaporkan SPT Masa Pajak Pertambahan Nilai dengan lebih mudah karena bisa dilakukan dimanapun dan tidak harus pergi ke Kantor Pelayanan Pajak sehingga tidak memerlukan waktu yang terlalu lama. 


\section{KESIMPULAN DAN SARAN}

\subsection{Kesimpulan}

Melalui penerapan ipteks yang telah diterapkan dapat disimpulkan bahwa PT Ciputra Internasional Cabang Manado mengenai penerapan e-Faktur terhadap pelaporannya telah sesuai dengan Undang-Undang dan peraturan perpajakan yang berlaku.

\subsection{Saran}

PT Ciputra Internasional Cabang Manado tetap mengikuti peraturan perpajakan yang berlaku mengenai pelaporan SPT Masa Pajak Pertambahan Nilai sehingga dapat meningkatkan efektifitas perusahaan. Dan sebaiknya pelaporan SPT Masa Pajak Pertambahan Nilai dilakukan jauh sebelum akhir bulan untuk mengatisipasi jika nantinya terjadi ganggunan pada aplikasi e-Faktur agar terhindar dari sanksi yang berlaku.

\section{DAFTAR PUSTAKA}

UU No. 42 Tahun 2009 tentang Perubahan Ketiga Atas UU No. 8 Tahun 1983 Tentang Pajak Pertambahan Nilai Barang Dan Jasa Dan Pajak Penjualan Atas Barang Mewah.

Peraturan Direktur Jenderal Pajak No. Per-01/PJ/2017 Tentang Penyampaian Surat Pemberitahuan Elektronik..

Peraturan Direktur Jenderal Pajak Nomor Per-31/PJ/2017 Tentang Perubahan Kedua Atas Peraturan Direktur Jenderal Pajak Nomor Per-16/PJ/2014 Tentang Tata cara Pembuatan Dan Pelaporan Faktur Pajak.

Lumikis, Riri I, Ilat, Ventje, 2018, "Ipteks Penghitungan Pajak Pertambahan Nilai (PPN) Berbasis E-Faktur (Studi Kasus Pada PT Berkat Rehobot)" "Jurnal Ipteks Akuntansi Bagi Masyarakat", Vol 02, No. 01, Hal 15-20.

Maria, Anzeli, Elim, Inggriani, Budiarso, Novi, 2018, “Analisis Penerapan E-Faktur Dalam Prosedur Dan Pembuatan Faktur Pajak Dan Pelaporan SPT Masa PPN Pada CV Wastu Citra Pratama" "Jurnal Riset Akuntansi Going Concern", Vol 13, No.03 (2018), Hal 445-455.

Sukardji, Untung. 2015. Pokok-Pokok PPN (Pajak Pertambahan Nilai) Edisi Revisi 2015. Penerbit PT RajaGrafindo Persada. Jakarta.

Firmansyah, Andik, Hidayati, Kusni, Pudjowati, Juliani, 2016, "Analisis Penerapan Perhitungan Pajak Pertambahan Nilai Dan Pelaporannya Pada CV Multi Karya Teknik (Berbasis E-Faktur) Di Sidoarjo" Prodi Akuntansi Fakultas Ekonomi Universitas Bhayangkara Surabaya.

Mardiasmo. 2018. Perpajakan Edisi Revisi 2018. Penerbit Andi. Yogyakarta.

Kansil, Rolando, 2015, "Analisis Penerapan Akuntansi Pajak Pertambahan Nilai Pada Pengusaha Kena Pajak Di PT Jaya Abadi Manado" "Jurnal Emba", ISSN 2303-1174, Vol 3, No. 1, Hal 426-434.

Achmad Tjahjono, Muh. Fakhir Husein. 2009. Perpajakan Pembahasan Berdasarkan UndangUndang Dan Aturan Pajak Terbaru. Penerbit STIM YPKN. Yogyakarta.

Daud, Andromedha, Sabijono, Harijanto, Pengerapan, Sonny, 2018, "Analisis Penerapan Pajak Pertambahan Nilai Pada PT Nenggapratama Internusantara" "Jurnal Riset Akuntansi Going Concern" Vol 13, No. 02 (2018), Hal 78-87.

Rahayu, Siti Kurnia. 2017. Perpajakan (Konsep Dan Aspek Formal). Penerbit Rekayasa Sains. Bandung. 